\title{
Market Overview of Enterprise Mashup Tools
}

\author{
Volker Hoyer ${ }^{1,2}$ and Marco Fischer ${ }^{1}$ \\ ${ }^{1}$ SAP Research CEC St. Gallen, 9000 St. Gallen, Switzerland \\ ${ }^{2}$ University of St. Gallen, 9000 St. Gallen, Switzerland \\ \{volker.hoyer, marco.fischer\}@sap.com
}

\begin{abstract}
A new paradigm, known as Enterprise Mashups, has been gain momentum during the last years. By empowering actual business end-users to create and adapt individual enterprise applications, Enterprise Mashups implicate a shift concerning a collaborative software development and consumption process. Upcoming Mashup tools prove the growing relevance of this paradigm in the industry, both in the consumer and enterprise-oriented market. However, a market overview of the different tools is still missing. In this paper, we introduce a classification of Mashup tools and evaluate selected tools of the different clusters according to the perspectives general information, functionality and usability. Finally, we classify more than 30 tools in the designed classification model and present the observed market trends in context of Enterprise Mashups.
\end{abstract}

Keywords: Enterprise Mashups, Internet of Services (IoS), Market Overview, Classification.

\section{Introduction and Motivation}

The networked information economy in the 21th century is characterized by a common-based peer production which represents a new model of economic production. According to Yochai Benkler who coined the term, "it refers to production systems that depend on individual action that is self-explained and decentralized rather than hierarchically assigned" [1]. Thereby, the creative energy of large number of people ("Wisdom of Crowds") is used to react flexible on continuous dynamic changes of the business environment. In the software development and consumption process, you can observe early signs of this commonbased peer production as well. Known as Enterprise Mashups, the actual business end-users are empowered to adapt their individual business workplaces according to their individual and heterogeneous needs [2. Driven by the consumer-oriented market, the Mashups paradigm is picked up in the enterprise context during the last two years.

Market research companies like Gartner [3, Forester [4] or the Economic Intelligence Unit [5] forecast a growing relevance of this paradigm in the next years. However, an overview of the upcoming Enterprise Mashup market regarding the provided functionality is missing. This article is devoted to a systematic analysis of the Mashup market to provide an overview of the current status.

A. Bouguettaya, I. Krueger, and T. Margaria (Eds.): ICSOC 2008, LNCS 5364, pp. 7087721 2008.

(C) Springer-Verlag Berlin Heidelberg 2008 
The reminder of this paper is structured as follows: Chapter two deals with a clear definition of the Enterprise Mashup paradigm. In chapter three, we present a model to classify Mashup tools according to the dimension functionality (editor and catalogue) and target group (consumer and enterprise). By means of eight case studies, chapter four analyses existing tools for the identified clusters. In addition, the developed classification model is applied. Finally, chapter five closes this article with a brief summary and an outlook of identified trends in the Enterprise Mashup market.

\section{Terms and Research Approach}

\subsection{Enterprise Mashups - Definition and Characteristics}

In literature, the exact definition of Enterprise Mashups or in general Mashups is open to debate. To build our research on a scientific foundation, we have investigated existing definitions by an in-depth literature analysis. Besides references from scientific articles published in international journals or conference proceedings, we also consider the current situation in the industry which has driven the paradigm. Regarding from a technical (6], [7, 8], 9] , [10), business (11, 12, [13]), application $([14,[15)$, consulting ([16], [17]), software vendor ([18], 19], [20] ) and community (Wikipedia [21]) perspective, we analyse 16 definitions.

First of all, there exists no general difference between definitions used in the scientific community and in the industrial world which has driven the terminology so far. The authors of the scientific papers define the term Mashup by their own and don't quote a primary reference. In almost all definitions, the resource composition style is named as the central characteristic of Mashups. They only differ from which resources are mashed. Besides content or data ([9], [1], [12], [13, 15, 19, 20], 21) according to the Web 2.0 data-centric approach, traditional application functionalities are also mentioned as Web-based resources ([18, [14, 30]). The history of the term itself is referred by many authors to the music hip hop style. Starting in the early 1970s, hip hop artists began mixing and matching beats from various sources, and then layering their own rhythmic vocals on top. This new art form proved highly popular with young people, and now constitutes one of the industry's most lucrative genres.

After a wide dissemination of the first consumer-oriented Mashups, the paradigm is also picked up in the context of enterprise applications. Even if software vendors [19] and some scientific authors introduced the term Enterprise Mashups 7], there exists no general difference to the original Mashup definition. Only the relation to existing concepts, in particular the Service-Oriented Architecture and the Web 2.0 philosophy are mentioned additionally. At the interface of this two converging principles, Enterprise Mashups put a visual face to the heavyweight Service-Oriented Architecture [18, 6], 7], 8] and can be interpreted as an evolution of SOA [18]. Therewith, they represent one technology to build "situational applications" [18 within hours to react flexible on changing business environments and follow an end-user centric approach [6]. 
Summering up and based on the literature review, we take the following summary as foundation for this work: "An Enterprise Mashups is a Web-based resource that combines existing resources, be it content, data or application functionality, from more than one resource in enterprise environments by empowering the actual end-users to create and adapt individual information centric and situational applications.".

\subsection{Lightweight Resource Composition}

In context of Enterprise Mashups a clear and wide established terminology is missing both in the industry as well as in the academic world. In the following section we present the significant components and terms used in the discussion of Enterprise Mashups. Figure 1 depicts the two different lightweight composition styles (wiring and piping) and classifies them in an Enterprise Mashup Stack [2] that is based on three layers: Resources, Widgets and Mashups.

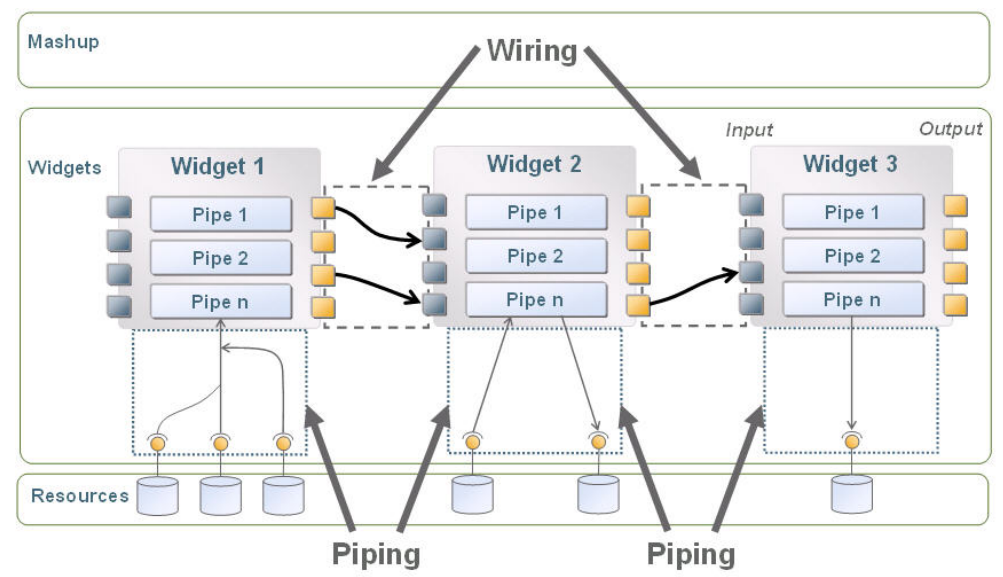

Fig. 1. Lightweight Composition with Enterprise Mashups (Piping vs. Wiring) 2]

Resources. The lowest layer contains the actual Web resources, be it content, data or application functionality. They represent the core building blocks of Enterprise Mashups and are the differentiator of the resource-centric paradigm. According to the lightweight Representational State Transfer (REST) architecture style 22, each Web-based resource can be addressed by a Universal Resource Identifier (URI). The resources itself are sourced via a well-defined public interface, the so called Application Programming Interfaces (APIs). They encapsulate the actual implementation from the specification and allow the loosely coupling of existing Web-based resources.

Widgets. Widgets represent application domain functions or information specific functions and put a visual face on the underlying resources. They are sourced 
via public APIs, and are responsible for providing graphical, simple and efficient user interaction mechanisms that abstract from the technical description (functional and non-functional) of the Web-based resources. The term used is widget, but some vendors are also using the wording gadget or badget.

Mashup. By assembling and composing a collection of widgets stored in a catalogue or repository, end-users are able to define the behavior of the actual application according to their individual needs. By aggregation and linking content of different resources in a visual and intuitive way, the end-users are empowered to create their own workspace which fits best to solve their heterogeneous business problems. No skills in programming concepts are required.

The central driver of Enterprise Mashups is the lightweight resource composition style by reusing building blocks in different contexts 2. As depicted in Figure 1, the composition takes place both on the resource layer (piping) and on the widget (wiring) layer. In reference to the UNIX shell pipeline concept, the piping composition integrates a number of heterogeneous Web-based resources defining composed processing data chains/ graphs concatenating successive resources. The output of each process is direct input to the next one. Aggregation, transformation, filter and sort functions adapt, mix and manipulate the content, data and application functionality of the Web-based resources. On the widget layer, the actual end-user is able to wire existing widgets together by interconnecting visually their input and output parameters.

\subsection{Research Approach}

This section is devoted to the presentation of the research approach applied. The goal of the research is to provide an overview about Enterprise Mashup tools. Based on an intensive analysis of more than 30 Mashup tools, we design a Mashup classification model to classify the heterogeneous tools. Thereby the analysis is done by means of three main criteria. First, a general information part consists of vendor information and about the tool itself (e.g., Mashup type and addressed target group). Second, the Mashup tools are analysed concerning their functionality (catalogue, mass collaboration and lightweight composition style [2]). Third, an analysis of the usability gives an answer how user-friendly a Mashup tool is. The developed classification model is applied by classify different Mashup tools. In addition, case studies for each cluster of the model describe the functionality of existing tools. Summering up, identified and observed market trends are presented.

\section{Classification Model}

After presenting the underlying research approach, this section presents a designed Mashup classification model. By means of an intensive analysis of different tools we identify two main differentiators: functionality/ property and target group. 


\subsection{Functionality/ Property}

Due to the innovative characteristic of Mashup tools, the provided functionalities cover a wide area reaching from catalogue to more visually editor functions.

Catalogue. A catalogue is a collection or library of existing resources and widgets dependent on which layer (resource or widget) you operate. By describing the resources by the resource provider or also by the actual end-user following the Web 2.0 philosophy, the user is enabled to search for relevant resources according to his individual and heterogeneous need. In addition to these organizational tasks, catalogues have also to mediate between the different resources types. As mentioned before, the power of the Enterprise Mashup paradigm is based on the integration and easily connection of different resource types might it be Web pages (HTML), Web Services (WSDL), databases or enterprise applications. In general, a catalogue is sub-divided into repository and adapter:

- An adapterintegrates existing resources in Mashup environments by mediate between different resource types both on syntactic and semantic level. To connect the resources, the adapter maps to a common protocol and internal format. For example, adapters scrape information from unstructured Web pages expressed in HTML or integrate complex Web Services with several input and output parameters into the Mashup environment by reducing the parameters.

- A repository organizes the growing number of resources and widgets in the Internet of Services. First of all, it comprises a registry in order to make them all retrievable via one single point of access. A user is so enabled to browse the existing widgets and resources. Also the efficient management and governance (e.g., service level agreement to ensure quality-of-service interaction) is part of the structural organization of a Mashup repository. The ad-hoc lightweight composition requires also a user-driven organization following the Web 2.0 philosophy. In that sense, end-users are enabled to rate, describe or recommend services.

Editor. An editor allows creating, modifying and aggregating of individual software applications by connecting resources retrievable from the catalogue. To address end-users characterized with no or only limited programming skills, the editor abstracts from the underlying programming interfaces through intuitive visual design environments following a "programming with the mouse" principle. The creating of ad-hoc enterprise applications is done within minutes or even hours instead of days or months. In contrast to traditional development environments focusing on actual programmers, Mashup editors don't separate between the design and runtime phase. These two phases are converging. According to the layer concept of the Enterprise Mashup Stack presented in chapter two, Mashup editors focus either on a presentation layer or on a transformation/ aggregation layer:

- Transformation/ Aggregation. combine data and content according to the lightweight resource composition style (piping) by reusing building blocks in different contexts. Information is sourced from several resources comparable with traditional EAI tools. 
- Presentation layer tools present content from disparate sources together in a unified view and run the composition. In that sense, the presentation tools focus by default explicitly on end-users and use the transformed and aggregated resources.

\subsection{Target Group}

In addition to the actual functionality of Mashup tools, we have to distinguish from the addressed target group. Driven by the consumer oriented market in the last years tools focus more and more on enterprise requirements which are different to the consumer requirements.

Consumer Mashups. A consumer Mashup tool is mainly aimed at individuals to easily create Mashups for private use, e.g. personalized browser page. The consumer Mashup is perhaps the best know type of Mashups. Consumer Mashups combine data elements from multiple sources, hiding this behind a simple unified graphical interface. Instead of opening several Web pages to view, for example, the weather forecast, the news and your private emails, the consumer is able to create an individual start page pulling the information from different sources.

Enterprise Mashups. They combine existing resources, be it content, data or application functionality, from more than one source in enterprise environments. In contrast to consumer Mashups, enterprise environments implicate additional requirements like security, quality or availability. In additional, Enterprise Mashups focus on integrating existing back-end systems. So, Enterprise Mashups have enormous potential to allow more rapid and much less expensive development of applications by emphasizing assembly over development, economies of scale by enabling high levels of reuse, and the consequent ability to rapidly get software solutions with the right data in the right place at the right time.

\section{Market Overview Mashup Tools}

In chapter four, we provide a market overview of existing Mashup tools by means of the presented classification model. Several vendors provide more than one feature; in this case we classify tools according to one capability in the case studies.

\subsection{Case Studies: Consumer Market}

Adapter. Dapper entered the Mashup market in 2005. Dapper's core business is to provide public Web-based Software as a Service (SaaS) tool for generating feeds from any Web page (e.g., RSS, XML, JSON, etc.). Dapper Factory 11 lets user extract and structure data from around the Web, and then create services based around this structured information. Dapper is aimed at consumer and expand their ability to integrate Web content into their personal live. Additionally,

\footnotetext{
1 http://www . dapper.net/
} 


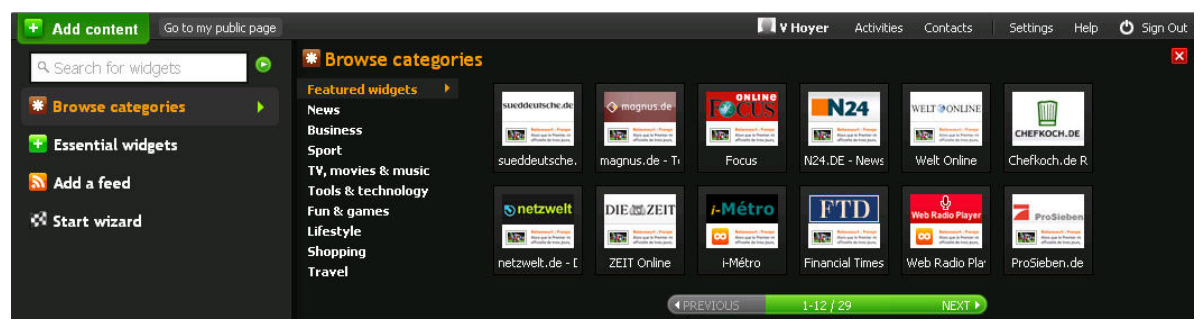

Fig. 2. Netvibes Ecosystem

Dapper provides a Web community, where user can access and share Dapper delivered feeds. Therefore is Dapper also a repository, but the main functionality is the Web-based wizard. For now, Dapper is a free and entirely Web-based service though they intend on providing revenue generators in the near future with an enterprise license.

Repository. Netvibes $2^{2}$ is one of the pioneers of personalized browser pages (presentation layer), and includes a huge repository of predefined resources. Netvibes let you assemble widgets, feeds, social networks, email, videos and blogs on one fully-customizable page. Netvibes introduced a beta version of the same name in 2006 and is much like iGoogle, and Microsoft Live, but has much less advertising and much more focus on the widgets, which are stored in the repository. Furthermore Netvibes Ecosystem 3 is a collection of user submitted modules or widgets. Widgets can be tagged, rated or commented and are findable through categories (e.g. business, news, education and so on) or browser search.

Transformation/ Aggregation. Microsoft develops, manufactures, licenses, and supports a wide range of software products for computing device. Microsoft decided to launch their first Mashup product in 2005, and recognized early, that there could be a potential in the market. Microsoft provides with Popfly 4 a public 3D Web-based consumer tool with a Mashup Creator to combine and aggregate widgets with the lightweight resource composition style (piping). Popfly has a rich user interface based on the Silverlight technology. Behind is a social network called Popfly Space for sharing, rating, and commenting user contributed Mashups. For this reason, Popfly is an editor as well as a repository of existing resources.

Presentation. Google Inc. offers with iGoogl5 a presentation tool for the Mashup market. Google's consumer platform aims to centralize all personal information in a personalized browser page. iGoogle includes the capability to add RSS feeds and Google gadget, similar to those available on Google desktop. Some of the themes are animated depending on weather conditions or the time

\footnotetext{
2 http://www.netvibes.com/

3 http://eco.netvibes.com/

4 http://www.popfly.com/

5 http://www.google.com/ig
} 


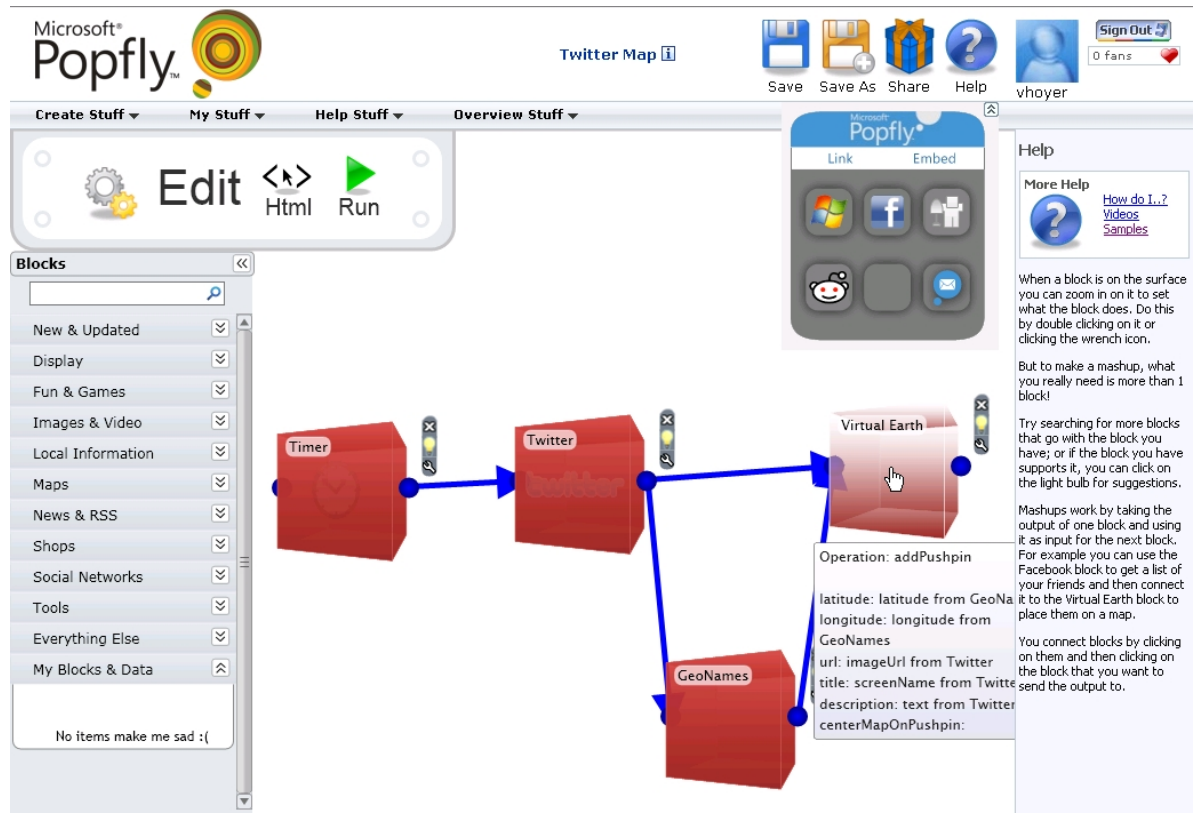

Fig. 3. Microsoft Popfly

in different areas. Furthermore the Google Gadgets API is public and allows anyone to develop a iGoogle gadget. Since May 2007, Google integrates a Gadget Maker, where users can create a special gadget that does not require the use of the Gadgets API. Thus iGoogle is a combination between a repository and front-end tool, but the main capability is to present content from different sources.

\subsection{Case Studies: Enterprise Market}

Adapter. Kapow Technologies is a standing vendor in the Mashup market, which already launched its product in 2001. Therefore, Kapow has been in production at many large consumer sites and enterprises for years. Kapow provides both an open community known as OpenKapow 6 as well as a desktop-based Mashup adapter called Kapow Mashup Server 7 . This commercial adapter focuses on information access, augmentation and scraping off Web-based information. Kapow uses robots to convert unstructured data form various sources into information feeds. Kapow's key feature is to turn Web pages into data sources with a wide range of data outputs (e.g., XML, HTML, CSV, and JSON).

Repository. IBM is a multinational computer technology and consulting corporation which manufactures and sells computer hardware and software, and offers

\footnotetext{
6 http://openkapow.com/Default.aspx

7 http://www.kapowtech.com/products.html
} 


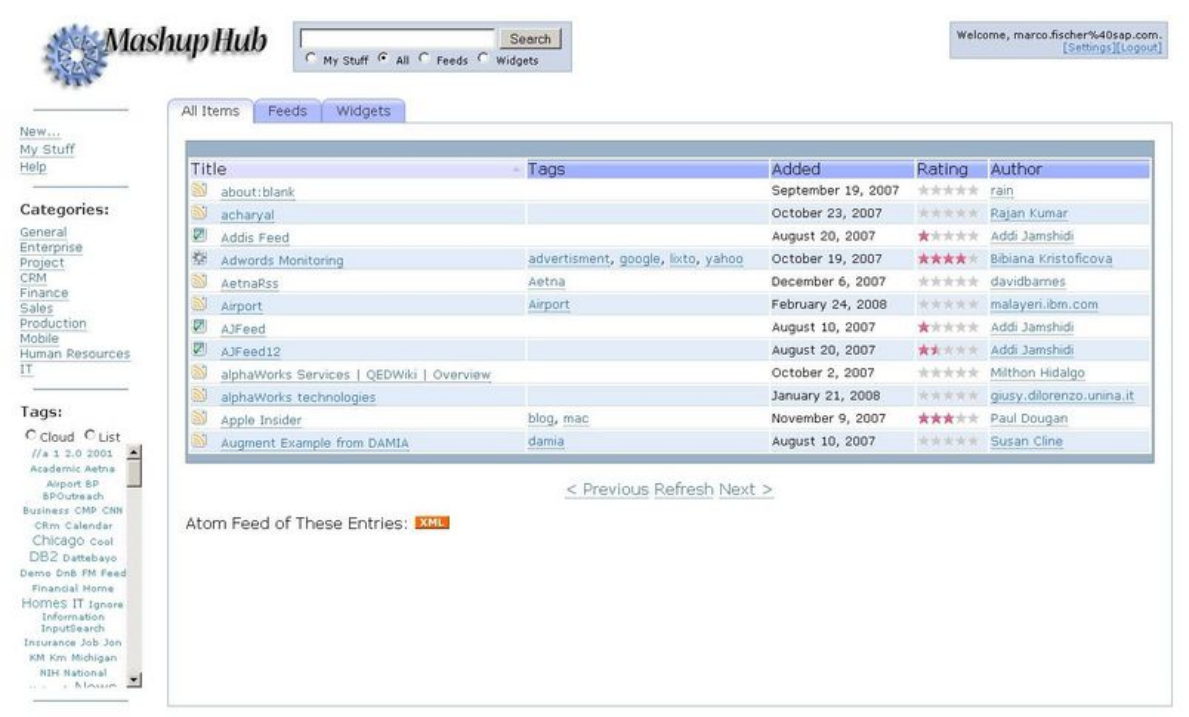

Fig. 4. IBM Mashup Hub

infrastructure services, hosting services in areas ranging from mainframe computers to nanotechnology. IBM launched with the Mashup Starter Kit its first Mashup Product in 2006. IBM Mashup Starter Kit consists of two technologies, and one of them is IBM's Mashup Hulb. Mashup Hub is primary a catalogue of feeds and widgets, which can be input for another IBM product QEDWiki. The repository allows to tag and rate resources and the aid of guided process flows for ease of use. IBM's Mashup Hub is also a Web-based editor to create feeds from different sources, (e.g., XML, SQL queries, spreadsheet) and supports therefore feed generation for enterprise data sources, which finally stored in the repository.

Transformation/ Aggregation. Yahoo provides a wide array of Internet services that cater to most online activities. They entered 2006 with its Web application product Yahoo! Pipes 9 in the Mashup market. Yahoo! Pipes provides a graphical user interface for building applications that aggregate Web feeds as depicted in Figure 5. Web pages, and other services, creating Web-based applications from various sources, and publishing those applications. Development is based on dragging resources from a toolbox and dropping them in work area, specifying data input, interconnecting gadgets through "pipes" and specifying data output format. At the moment Pipes has limitations for enterprise use, but it can handle simple business needs by now.

Presentation. The company JackBe was founded in 2002 as an AJAX widget company to later find itself targeting the IT enterprise market. JackBe launched

\footnotetext{
${ }^{8}$ http://services.alphaworks.ibm.com/mashuphub/

9 http://pipes.yahoo.com/pipes/
} 


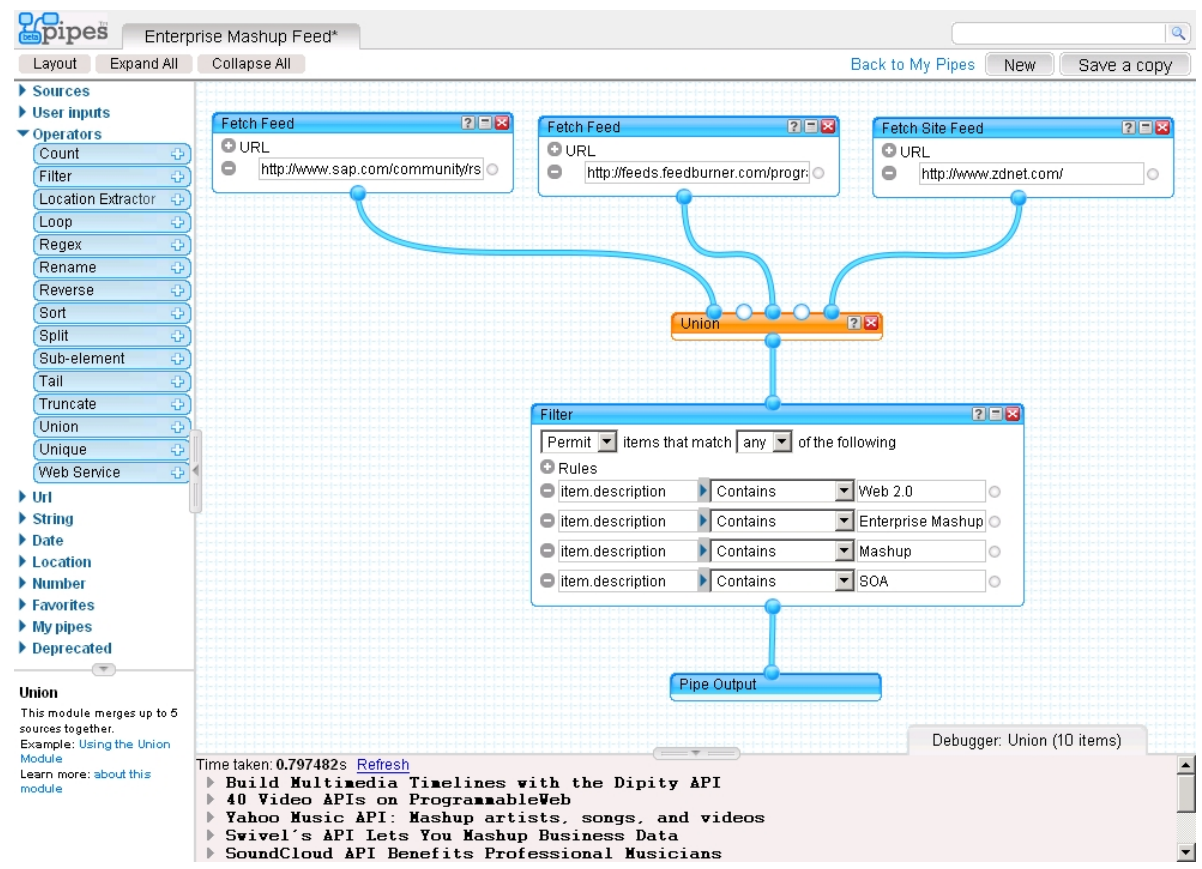

Fig. 5. Yahoo Pipes

with Presto a series of Enterprise Mashup solutions, consist of four components. In this case we cater to JackBe's front-end tool Presto Edge Enterprise Mashup Server 10 . Presto Edge allows publishing of Web services and provides collaboration and execution on the presentation layer. Sources, e.g. from another JackBe tool can easily piece together to a new application. JackBe also offers predefined solutions in security, administration and management capabilities.

\subsection{Market Overview}

After presenting selected Mashups tools for the different clusters according to the designed classification model, we classify more than 30 Mashup tools, shown in Figure 6. Several vendors provide more than one capability according to the classification model and therefore these vendors are classified in multiple clusters. For example, IBM QEDWiki is mentioned as an editor and a catalogue.

The market overview identifies a huge amount of vendors, which cavort in the Mashup space. Tools and services like Pageflakes, iGoogle aimed at consumer and non-technical users to create and publish their own Mashups. Consumer can easily generate own personalized browser pages with news, feeds and different gadgets. But Mashups seem to be not only a bauble for consumer, more and more enterprise vendors enter the market from the application integration, information

\footnotetext{
10 http://www .jackbe.com/products/edge.php
} 


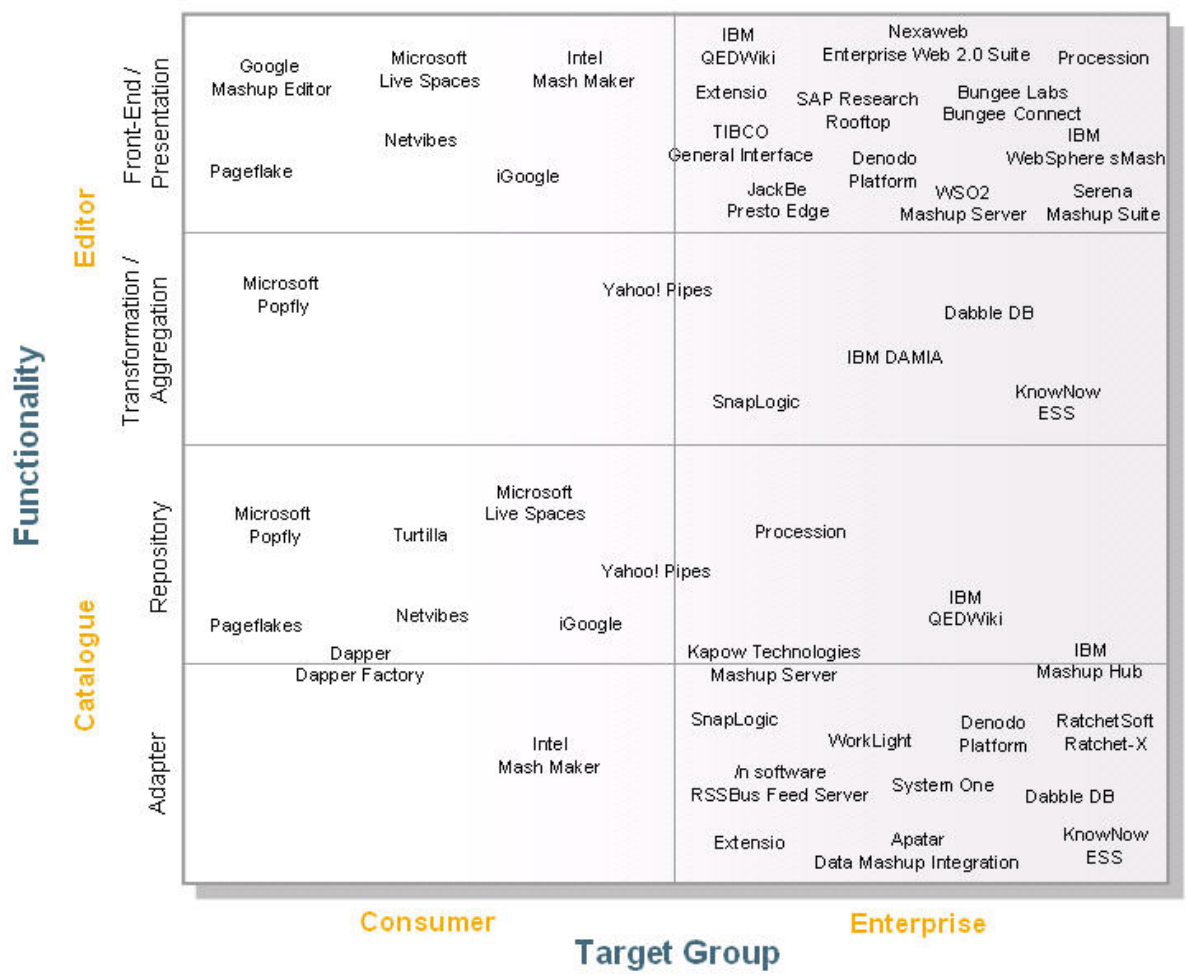

Fig. 6. Classification of Mashup Tools

integration, rich Internet application and enterprise portal markets. In the last two and a half years enterprises like Microsoft, IBM and Serena placed new products into the Mashup market. But this is just the beginning, because the market is still in a state flux.

Additionally the trend of extremely individualized worker [23] means that enterprises also must observe public Mashup technologies to measure their potential for enterprise use. Interest in Mashup tools is also affecting the horizontal portal market and multiple portal vendors already support Mashups to a limited degree [24]. Furthermore CRM and ERP software enterprises, which are not mentioned in the figure above, integrate Mashup solutions in their existing enterprise software (e.g., vtiger, Salesforce.com, or Oracle). Thus, non Mashup specialists come into the market and Mashup tools getting closer to mainstream business use - they are moving into the enterprise as mentioned before. Companies have significant challenges to integrate information from various resources and Mashups can be an answer of this problem. They recognize the theoretical potential behind Mashup tools and plan to use them in the next years anymore [5]. In addition to positives of the market, enterprises should be aware, that Enterprise Mashup tools still in its infancy and aspects like security, administration, new and necessary IT strategies are not in detail discussed or implemented by now. 


\section{Conclusion}

The opportunity of remixing internal and external resources more rapid and with much less expensive development into entirely new applications has captured the software industry. Niche players, visioniers and challengers provide a wide range of different Mashup tools and platforms to grip market share. This market overview analyses several tools and offers an overview of the existing market with the assistance of a Mashup classification model. The analysis shows that Enterprise Mashups still in flux and the market will be in move over the next years. New enterprises will enter the market, because Mashup tools affect the whole software industry. A new report from Forrester Research predicts that Mashups will be coming to the enterprise in a big way with a USD 700 Mio market by 2013 [4. Additionally the way workers view their workplace is changing. New employees have different skills and expectations, because they are grow up with IT and know how to customize and individualize almost everything [25].

Nevertheless, there are still issues and lacks in existing tools, like a missing screenflow design, semantic aspects and the covering of enterprise typical requirements like security or reliability. In frame of the EU funded project FAST [26]11, we are currently developing a new visual environment following a user-centric approach that will facilitate the development of complex widgets required in business environments. Besides these technical challenges, the project focuses on the creation of business relevant widgets. As identified in the evaluation of the different Mashup tools, the actual content encapsulated by widgets is still missing. In future, a growing number of business widgets will be a critical success factor for a wide dissemination of the Mashup paradigm in corporate environments.

Acknowledgments. This paper has been created closely to research activities during the EU-funded project FAST (INFSO-ICT-216048) [26].

\section{References}

1. Benkler, Y.: The Wealth of Networks. How Social Production Transforms Markets and Freedom. Yale University Press, New Haven (2006)

2. Hoyer, V., Stanoevska-Slabeva, K., Janner, T., Schroth, C.: Enterprise Mashups: Design Principles towards the Long Tail for User Needs. In: IEEE International Conference on Services Computing (SCC), vol. 2, pp. 601-602 (2008)

3. Bradley, A., Gootzit, D.: Who's Who in Enterprise Mashup Technologies. Gartner Research (2007)

4. Young, G., Daley, E., Gualtieri, M., Lo, H., Ashour, M.: The Mashup Opportunity. Forrester (2008)

5. The Economist Intelligence Unit: Serious Business - Web 2.0 goes Corporate. The Economist Intelligence Unit (2007)

6. Liu, X., Hui, Y., Sun, W., Liang, H.: Towards service composition based on mashup. In: Proceedings of the IEEE International Conference on Service Computing (SCC 2007), pp. 332-339 (2007)

11 http://fast.morfeo-project.eu/ 
7. Janner, T., Canas, V., Hierro, J., Licano, D., Reyers, M., Schroth, C., Soriano, J., Hoyer, V.: Enterprise Mashups: Putting a face on next generation global SOA. In: Benatallah, B., Casati, F., Georgakopoulos, D., Bartolini, C., Sadiq, W., Godart, C. (eds.) WISE 2007. LNCS, vol. 4831, Springer, Heidelberg (2007)

8. Soriano, J., Lizcano, D., Canas, M., Reyes, M., Hierro, J.: Foster Innovation in a Mashup-oriented Enterprise 2.0 Collaboration Environment. System and Information Sciences Notes 1(1), 62-68 (2007)

9. Kultathuramaiyer, N.: Mashups: Emerging application development paradigm for a digital journal. Journal of Universal Computer Science 13(4), 531-542 (2007)

10. Daniel, F., Matera, M., Yu, J., Benatallah, B., Saint-Paul, R., Casati, F.: Understanding UI Integration. A Survey of Problems, Technologies, and Opportunities. IEEE Internet Computing 11(3), 59-66 (2007)

11. Dearstyne, B.: Blogs, mashups, wikis oh my. Information Management Journal 41(4), 24-33 (2007)

12. O'Brien, D., Fritzgerald, B.: Mashups, remixes and copyright law. Internet Law Bulletin 9(2), 17-19 (2007)

13. Gerber, R.: Mixing it up on the web: Legal issues arising from the internet mashup. Intellectual Property and Technology Law Journal 18(8), 11-14 (2007)

14. Miller, C.: A beast in the field: The google maps mashup at gis/2. Cartographica The International Journal for Geographic Information and Geovisualization 41(3), 187-199 (2007)

15. Cho, A.: An introduction of mashups for health libranrians. Journal of the Canadian Health Libraries Association 28(1), 19-22 (2007)

16. The Economist: Mashing the web. The Economist - Special Section 376(8444), 4 (2005)

17. Hof, R.: Mix, match, and mutate. Business Week Magazine (2005)

18. Watt, S.: Mashups - the evolution of the soa, part 2: Situational applications and the mashup ecosystem (2007),

http://www.ibm.com/developerworks/webservices/library/ ws-soa-mashups2/

19. Clarkin, L., Holmes, J.: Enterprise mashups. The Architecture Journal 13 (2007)

20. Salesforce: Mashups: The what and why (2007), http://wiki.apexdevnet.com/index.php/

21. Wikipedia: Mashups (2008), http://en.wikipedia.org/

22. Fielding, R.: Architectural styles and the design of network-based software architectures. Ph.D. Thesis (2000)

23. Morello, D., Burton, B.: Future Worker 2015. Extreme Individualization. In: Garnter Symposium ITxpo, Orlando (2005)

24. Gootzit, D., Phifer, G., Valdes, R.: Magic Quadrant for horizontal Portal Products. Garnter Research (2007)

25. Cherbakov, L., Bravery, A., Goodman, B., Pandya, A., Bagget, J.: Changing the corporate it development model: Tapping the power of grassrots computing. IBM System Journals 46(4) (2007)

26. FAST: EU Project FAST (INFSO-ICT-216048) (2008), http://fast.morfeo-project.eu/ 


\section{Appendix: Evaluation Matrix}

\begin{tabular}{|c|c|c|c|c|c|c|c|c|}
\hline Evaluation Criteria & 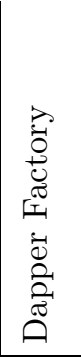 & $\begin{array}{l}\underset{0}{0} \\
0 \\
0 \\
0 \\
0\end{array}$ & 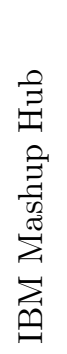 & 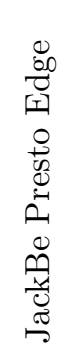 & 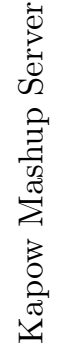 & 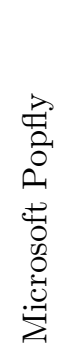 & $\begin{array}{l}\frac{0}{0} \\
\frac{0}{1} \\
\frac{1}{0} \\
z \\
Z\end{array}$ & 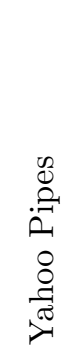 \\
\hline \multicolumn{9}{|l|}{ Product Information } \\
\hline \multicolumn{9}{|l|}{ Mashup Type } \\
\hline Editor & & $\mathrm{x}$ & & $\mathrm{x}$ & & $\mathrm{x}$ & $\mathrm{x}$ & $\mathrm{x}$ \\
\hline Catalogue & $\mathrm{x}$ & $\mathrm{x}$ & $\mathrm{x}$ & & $\mathrm{x}$ & $\mathrm{x}$ & $\mathrm{x}$ & $\mathrm{x}$ \\
\hline \multicolumn{9}{|l|}{ Target Group } \\
\hline Consumer & $\mathrm{x}$ & $\mathrm{x}$ & & & & $\mathrm{x}$ & $\mathrm{x}$ & $\mathrm{x}$ \\
\hline Enterprise & & & $\mathrm{x}$ & $\mathrm{X}$ & $\mathrm{x}$ & & & $\mathrm{x}$ \\
\hline \multicolumn{9}{|l|}{ Functionality } \\
\hline \multicolumn{9}{|l|}{ Mashup Catalogue } \\
\hline Number of resources ${ }^{a}$ & 2.000 & n.a. & 150 & n.a. & 6.000 & 150 & 172.000 & 1.000 \\
\hline Number of resource types ${ }^{b}$ & 7 & 4 & 6 & 5 & 7 & 3 & 3 & 4 \\
\hline Query and search capabilities & $\mathrm{x}$ & $\mathrm{x}$ & $\mathrm{x}$ & $\mathrm{x}$ & $\mathrm{x}$ & $\mathrm{x}$ & $\mathrm{x}$ & $\mathrm{x}$ \\
\hline Creation of widgets & $\mathrm{x}$ & $\mathrm{x}$ & & $\mathrm{x}$ & $\mathrm{x}$ & $\mathrm{x}$ & $\mathrm{x}$ & $\mathrm{x}$ \\
\hline External catalogues & & & $\mathrm{x}$ & & & & & \\
\hline \multicolumn{9}{|l|}{ Mass Collaboration } \\
\hline Tagging & $\mathrm{x}$ & $\mathrm{x}$ & $\mathrm{x}$ & n.a. & $\mathrm{x}$ & $\mathrm{x}$ & $\mathrm{x}$ & $\mathrm{x}$ \\
\hline Rating & & $\mathrm{x}$ & $\mathrm{x}$ & n.a. & $\mathrm{x}$ & & $\mathrm{x}$ & $\mathrm{x}$ \\
\hline FAQ & $\mathrm{x}$ & $\mathrm{x}$ & $\mathrm{x}$ & $\mathrm{x}$ & $\mathrm{x}$ & $\mathrm{x}$ & $\mathrm{x}$ & $\mathrm{x}$ \\
\hline Blog & $\mathrm{x}$ & $\mathrm{x}$ & & $\mathrm{x}$ & $\mathrm{x}$ & $\mathrm{x}$ & $\mathrm{x}$ & $\mathrm{x}$ \\
\hline Forum & $\mathrm{x}$ & $\mathrm{x}$ & $\mathrm{x}$ & $\mathrm{x}$ & $\mathrm{x}$ & $\mathrm{x}$ & $\mathrm{x}$ & $\mathrm{x}$ \\
\hline \multicolumn{9}{|l|}{ Lightweight Composition } \\
\hline Screenflow design & & & & & & & & \\
\hline Visual Wiring & & & & $\mathrm{x}$ & & $\mathrm{x}$ & & \\
\hline Visual Piping & & & & $\mathrm{x}$ & & $\mathrm{x}$ & & $\mathrm{x}$ \\
\hline \multicolumn{9}{|l|}{ Usability } \\
\hline \multicolumn{9}{|l|}{ End-User Interface } \\
\hline Ease of use & $\mathrm{x}$ & $\mathrm{x}$ & $\mathrm{x}$ & & & $\mathrm{x}$ & $\mathrm{x}$ & $\mathrm{x}$ \\
\hline Drag-and-Drop & & $\mathrm{x}$ & & $\mathrm{x}$ & & $\mathrm{x}$ & & $\mathrm{x}$ \\
\hline Guided process flows & $\mathrm{x}$ & $\mathrm{x}$ & $\mathrm{x}$ & $\mathrm{x}$ & $\mathrm{x}$ & $\mathrm{x}$ & & $\mathrm{x}$ \\
\hline Performance & $<2 \mathrm{sec}$ & $<2 \mathrm{sec}$ & $<1 \mathrm{sec}$ & $<1 \mathrm{sec}$ & & $<2 \mathrm{sec}$ & $<1 \mathrm{sec}$ & $<2 \mathrm{sec}$ \\
\hline \multicolumn{9}{|l|}{ Help } \\
\hline Demos & $\mathrm{x}$ & $\mathrm{x}$ & $\mathrm{x}$ & $\mathrm{x}$ & $\mathrm{x}$ & $\mathrm{x}$ & $\mathrm{x}$ & $\mathrm{x}$ \\
\hline Tutorials & & $\mathrm{x}$ & & $\mathrm{x}$ & $\mathrm{x}$ & $\mathrm{x}$ & $\mathrm{x}$ & $\mathrm{x}$ \\
\hline
\end{tabular}

a Estimated number

$b$ Resource types can be: Widgets, ATOM, CSV, data base, HTML, JSON, RSS, WSDL, XML, etc. 